\title{
Enriching and Enhancing Life Skills by Learning Science among Adolescents
}

\author{
S. D. Thanga Shyla \\ Department of Education, St. Joseph University in Tanzania, Dar es Salaam, United Republic of Tanzania
}

Email address:

thangashyla@gmail.com

\section{To cite this article:}

S. D. Thanga Shyla. Enriching and Enhancing Life Skills by Learning Science among Adolescents. Science Journal of Education. Special Issue: Science Learning in Higher Education. Vol. 3, No. 4-1, 2015, pp. 21-24. doi: 10.11648/j.sjedu.s.2015030401.15

\begin{abstract}
Science has attained its high interest and its relations with technology and society is more valuable. The key aim of science learning should be to realize and recognize the world of nature. The usual curiosity of young learners is to develop the process of exploring and understanding the natural world they live in. Every individual should motivate to understand the surroundings. The experiences gained by science can promote positive attitude, motivate students, problem solving and help them to live as an useful citizen to the society. Adolescents are the valuable young learners worldwide with stress and storm and need to shape the total personality. Learning science should help them to develop innovative skills for their future work and social life. Thus, this article reveals about the life skills which can be develop and inspired by science Learning.
\end{abstract}

Keywords: Science, Learning, Adolescents, Life Skills, Team skills, Communication, Leadership, Decision Making, Self-Management, Professionalism

\section{Introduction}

The modern world of education needs the improved science learning and exciting opportunities for meeting the demand in life. Science is the way of thinking and understanding the environment. It starts from observations, explanations, experiments, conclusions and applications.

The challenge is to develop a mindset that science learning should be pursued with the same rigorous standards of study as scientific research. By implementing more effective pedagogical approaches of learning science will benefit to develop life skills to every student in every college and university.

\section{Learning}

Teaching-learning process is dynamic, inspirational, goaloriented, innovative and novel. Education as the process of bringing about behavior changes in the recipients can be realistic only through.

Teaching-learning process is dynamic, inspirational, goaloriented, innovative and novel. Education as the process of bringing about behavior changes in the recipients can be realistic only through quantitative teaching and learning by prospective methods. Education whatever be its goals and objectives, involves learning. Learning is modification arising out of learning may be cognitive, affective, sensory motor or an amalgam of all these in different proportions. Human learning may occur at different levels of complexity. Learning takes place in the way of it is desired. Its effectiveness is validated by suitable testing means periodically. Real learning gets to the heart of what it is to be human. We become able to re-create ourselves (Senge, 1990: 139).

Science education activities should enhance children's understanding of the role in the development of scientific understanding. Make sense of practices and meta-cognition used to assess others ideas and thoughts are essential competencies that need to be valued elements of science learning. The importance of developing the skills of life society should be correlated with science activities. The same can be said for having understanding of tools available and their appropriate use.

The overall goal of science education can be viewed as providing the future adult citizens with the opportunity to develop the knowledge, skills and attitudes encompassed in the notion of scientific literacy. If this is achieved they will be able, as informed members of society, to participate in informed decision-making about scientific phenomena and issues affecting them and the communities they live in. Scientific investigations and then sharing the result will 
require science learning that introduce the scientist's world to all learners, both by asking the learners to do science, and by bringing the scientist's world into the classroom through various activities.

\section{Purposes of Learning Science}

The outcome of science education should be that students will have developed the knowledge, skills, attitudes and values that will allow them to take an informed situation on scientific issues and problems that may be facing them and the society they live in at the time. They should have developed an enquiring approach and the awareness and skills that will allow them to find the answers of the problems. A key aim of science education should be to recognize the natural curiosity that young students bring to the process of exploring and understanding the natural world they live in. These attitudes must be valued and enhanced, ensuring that these creative perspectives are retained into lifelong.

The description for science learning should be:

- Develop all people an understanding of the nature of science, its role in modern society, its potential and its limitations as a guide to action

- Identify and foster those who have the potential to carry special responsibilities in science and science-related spheres of human endeavour - the scientists, the engineers, the communicators, the technicians

\section{Adolescents}

Adolescents are the group of individuals aged between 12 -18 . This is the stage of stress and storm. It is particularly hard time for students. They are experiencing all kinds of new changes in their bodies and in their feelings. As well, they often feel misunderstood as they are struggling to leave behind their childhood and become adults. Adolescence has commonly been characterized by issues such as rebellious behaviour, lying, cheating, school performance problems, negative attitudes, disobedience and disrespect, sibling rivalry, drug and alcohol abuse, pressures from peers, depression, and issues of sexuality. It is a period of multiple transitions involving education, training, employment and unemployment, as well as transitions from one living circumstance to another. A thorough understanding of adolescence in society depends on information from various viewpoints, including psychology, biology, history, sociology, education, and anthropology. Within all of these viewpoints, adolescence is viewed as a transitional period between childhood and adulthood, whose cultural purpose is the preparation of children for adult roles.

\section{The Role of Science in Adolescents Life}

In the early stages, the attraction on science for learners and teachers lies in its pertinence and utility; gradually its academic status grows and its internal logic and discipline become increasingly influential in the choice of content. Now science has reached the last stage, and has come to broaden the objectives to include an understanding of science in its external relations with technology and society. An aim of science should be the development of both procedural knowledge and skills by the learners involved. Students of the modern world should develop the skills to plan processes that enable them to find a reasonable answer to their questions. Science education activities should enhance adolescents understanding of the role plays in the development of scientific understanding. Life skills make sense of experiences and meta-cognition used to evaluate others ideas and thoughts are essential competencies that need to be valued elements of science education programmers. The importance of developing the skills of life through science activities cannot be underestimated.

\section{Life Skills}

Life skills are abilities for adaptive and positive behaviour that enable us to deal effectively with the demands and challenges of everyday life, http://en.wikipedia.org/wiki/Life_skills - cite_note-1in other wordspsychosocialcompetency.http://en.wikipedia.org/wiki/L ife_skills - cite_note-2They are a set of talents acquired viateachingor direct experience that are used to handle problems and commonly encountered in dailyhumanlife. The World Health Organization(WHO) defined life skills as "abilities for adaptive and positive behavior that enable individuals to deal effectively with the demands and challenges of everyday life". They represent the psycho and social skills that determine value of behaviour and include reflective skills such as problem-solving and critical thinking, and personal skills such as self-awareness, and to interpersonal skills. These skills are usually associated with managing and living a better quality of life. They help the adolescents to accomplish ambitions and live to full prospective.

\section{Dimensions of Life Skills}

There is no definitive list of life skills. Certain skills may be more or less relevant to adolescents depending on their life circumstances, culture, beliefs, geographic location, etc.

\subsection{Team Work}

For small groups to function effectively in a course context, students must attend to both the climate within their group and the process by which they accomplish their tasks. Critical to a healthy climate and an effective process are strong communication skills. Below you will find the basic characteristics of effective communicators, plus tips to help students with group climate and process. To work together successfully, group members must demonstrate a sense of cohesion. Cohesion emerges as group members' exhibit the following skills openness, trust, self-disclosure, support and respect. 


\subsection{Leadership}

It is the action of leading a group of people or an organization, or the ability to do this. Leaders help themselves and others to do the right things. They set direction, build an inspiring vision, and create something new. Leadership is about mapping out where you need to go to "win" as a team or an organization; and it is dynamic, exciting, and inspiring. Leadership involves to motivate $\&$ direct others, taking responsibility for the direction \& actions of a team, setting objectives, organising\& motivating others, taking the proposal, persevering when things are not working out, taking a positive attitude to failure, accepting responsibility for mistakes/wrong decisions, being flexible and prepared to adapt goals in the light of changing situations. Giving guidance, bountiful direction, authority, control, management and supervision are some of the important duties of a leader.

\subsection{Decision Making}

Adolescents often find it hard to make decisions unavoidably they have to make decisions all the time, some are more important than others. Some people put off making decisions by endlessly searching for more information or getting other people to offer their recommendations. Others resort to decision making by taking a vote, sticking a pin in a list or tossing a coin. Thus, Decision Making is the act of choosing between two or more courses of action.

\subsection{Self-Management}

Self management in other words known as personal development. Each individual is responsible for everything that happens in their life. Everyone should learn to accept total responsibility for their life. If anyone unable to manage, then letting others to control of their life. Self care, individual control of health care, control of action, use new opportunities in exciting and new-life experience are some of the characteristics of self-management. The critical elements of self-management include setting goals, monitoring behavior, and evaluating progress and self reinforcement.

\subsection{Professionalism}

The Merriam-Webster dictionary defines professionalism as "the conduct, aims, or qualities that characterize or mark a profession or a professional person"; and it defines a profession as "a calling requiring specialized knowledge and often long and intensive academic preparation."

\section{Learning Broader Skills}

Today students should acquire many skills hence a teacher should help the students to acquire the following life and carrier skills which is possible by science learning.

(i) Flexibility and Adaptability: These two are the corner stone of science learning. It includes options for how to learn in various ways that are flexible and adaptable to the students' background knowledge, abilities and preferences.

(ii) Initiative and Self- direction: Science learning requires the students to take the initiative and selfdirected as they choose which learning opportunities to experience.

(iii) Social and Cross- cultural skills: Students learn social skills of working with whoever was at the same point of learning - not waiting until their friend caught up or assuming they were ready to move on just because their group did. This dynamic and often self-directed grouping process gave students an abundance of practice at social skills. The students also acquire the key social skills of politeness and patience.

(iv) Productivity and Accountability: Students are held completely accountable for their own learning in Science learning. The students were accountable and productive in order to progress through the course.

(v) Leadership and Responsibility: Students are responsible for their learning. There was no way they could not be. The students choose which activities to do learn the content. The students determine when they were ready for a quiz, not the teacher. The students themselves requested the quizzes and labs when they were ready. The students were responsible for tracking their own progress and for keeping an appropriate pace in the course.

(vi) Self-discipline Today discipline is the major problem in all over the world. It is a problem for teachers to handle the students in school also. Education only helps the students to develop discipline. Instead of forcing discipline teachers can make them to follow self discipline. Using proper teaching learning methods teachers can develop self- discipline among students. Mastery learning is such a model, which helps the students to develop self discipline among them. Using some strategies of mastery learning model, self discipline as well as academic achievement also can increase.

\section{Enhancing Life Skills}

Practicing life skills leads to qualities such as self-esteem, sociability and tolerance, competencies to take action, generate change, and capabilities of decision making. Knowledge of the process of science is important for individuals when evaluating conflicting perspectives. The notion of acceptable evidence can be a cornerstone in the process of accepting or rejecting new or changed ideas and perspectives. Attracting enthusiastic, skilled and knowledgeable students to careers in science and technology remains an important aim of science learning. All students must be given the opportunity to consider science as a worthwhile career. This will require science learningprogrammes that introduce the scientist's world to all learners, both by asking the learners to do science, i.e., 
planning investigations to find answers to problems and then applying their findings in real situations, and by bringing the scientist's world into the classroom through visits, talks, stories, etc. These strategies are intended to build a student's independence and ability to engage in life skills. The power of science learningand its impactcan build a feeling of control over one's own behavior. It will control an adolescent's behavior and get high result with low effort.

\section{Conclusion}

Life skills are thus specifically different from physical or perceptual motor skills, such as practical or wellbeing skills, as well as from livelihood skills, such as crafts, money management and entrepreneurial skills. Science education can be designed to be complementary to life skills education, and vice versa. But there are some basic fundamentals that every individual needs to master in order to succeed in and enjoy his/her life. The vast majority of professionals today have not received the training, information, understanding or knowledge they need to ensure they'll remain on a positive track and build a successful life that will be fruitful, productive and successful as the years go on. Adolescents should have a clear view of what constitutes their life, what characteristics to the people around them and should show some approachable characteristics for their livelihood.

Life skills and related terms are used to indicate a desire to teach processes of thinking and learning that can be applied in a wide range of real-life contexts and lead higher order thinking which is said to be complex thinking that requires effort and produces valued outcomes.

\section{References}

[1] Ediger, Marlow \&Rao, Bhaskara D. (2006). Philosophy and curriculum. New Delhi: Discovery Publishing House.

[2] Kelvin Seifert and Rosemary Sutton. (2009). Educational Psychology. 2nd Edition. Jacobs Foundation: Zurich, Switzerland.
[3] Georgia, Aimao Zhang. (2012). Peer Assessment of Soft Skills and Hard Skills, Journal of Information Technology Education: Volume $11 . \quad$ Assessed from http://www.skillsyouneed.com/general/life-skills.html

[4] Ian Milne, Aims and Goals for Science Education, Editorial New Zealand Science Teacher, 107 October 2004.

[5] Pat Crawford, Suzenne Lang, Wendy Fink, Robert Dalton, Laura Fielitz. (2011). Comparative Analysis of soft Skills: What is important for new Graduates? Michigan State University.

[6] College of Agriculture and Natural Resources, A joint study with the association of public and land grand Universities and the university industry consortium.

[7] Senge. (1990). Teaching and learning. New Delhi: Discovery Publishing House.

[8] Gerlach, Vernon S. \& Ely, Donald. (1980). Teaching and media: A Systematic Approach (2nded.). New York: Prentice Hall.

[9] Good, Carter V. (1973). Dictionary of education. New York: McGraw Hill.

[10] Good, Thomas L. (2008). 21st century education: A reference handbook, Vol 1. New Delhi: A Sage reference publications

[11] Kolb, D.A. (1984). Experiential Learning: Kolb's learning styles. Englewood Cliffs, NJ: Prentice-Hall.

[12] Shyla, S. D. Thanga\& Dharma Raja, B. William. (2012c). Teaching broader skills using mastery learning model. Paper presented in National Seminar conducted on Nagercoil: SreeAyyappa College of Arts and Science \& KAAS.

[13] Shyla, S. D. Thanga\& Dharma Raja, B. William. (2012d). Self discipline by dint of mastery learning. Paper presented in the International conference on Revamping Qualities in Higher Education. Trinelveli: ManonmaniamSundaranar University.

[14] Morgan, Kelly (1997). Mastery learning in the science class room. Virginia: NSTA press, 7.

[15] James Manktelow, What is Leadership?Assessed on 6.6.2015 from http://www.mindtools.com/pages/article. 